\title{
Kinetics and solvent effects in the synthesis of ionic liquids: imidazolium
}

\author{
Jay C. Schleicher† and Aaron M. Scurto* \\ Received 19th May 2008, Accepted 5th February 2009 \\ First published as an Advance Article on the web 26th February 2009 \\ DOI: $10.1039 / \mathrm{b808364a}$
}

Ionic liquids (ILs) are being considered as a promising class of potentially environmentally-friendly ("green") solvents and materials for use in a variety of applications. However, ionic liquids are conventionally synthesized by batch, without known kinetics, in non-sustainable solvents. For ILs to be a truly "green" technology for widespread use, they must themselves be made in a correspondingly benign manner for low cost, as enabled by process development. This investigation will illustrate the kinetics and large solvent effects in the synthesis of 1-hexyl-3-methyl-imidazolium bromide in 10 different solvents: acetone, acetonitrile, 2-butanone, chlorobenzene, dichloromethane, dimethyl sulfoxide (DMSO), ethyl formate, ethyl lactate, methanol, and cyclopentanone. The kinetic rate constant for the synthesis in DMSO is over an order-of-magnitude larger than that in methanol. While the kinetic rate of these type of $\mathrm{S}_{\mathrm{N}} 2$ reactions is generally known to increase with solvent "polarity", multi-parameter solvent descriptors, e.g. of Kamlet and Taft, are required to quantify these effects in a Linear Solvation Energy Relationship. These relationships are used with environmental and toxicity databases, such as the Rowan Solvent Selection Table, to rapidly optimize the solvent for favorable kinetics and minimal human and environmental impact.

\section{Introduction}

Ionic liquids (ILs) have been touted as the next great class of environmentally-friendly solvents due to their molecularly "tunable" properties and lack of volatility. New applications are being developed at a rapid pace. ILs have shown promise in enhancing catalytic activity, selectivity, stability and ability for recycling in various catalyzed reaction systems, such as hydroformylation reactions, ${ }^{1,2}$ and even in a wide range of biocatalytic transformations. ${ }^{3}$ ILs have a number of uses in various separation process. For instance, ILs can "break" a number of azeotropes, ${ }^{4}$ separate gases,${ }^{5}$ including refrigerant gases, ${ }^{6}$ desulfurize diesel fuel $;^{7}$ dissolve and process cellulose and other carbohydrates; ${ }^{8}$ are involved commercially in a biphasic acid scavenging processes; ${ }^{9}$ etc. In the field of analytical chemistry, ILs can be used as stationary phases in chromatography and other separation and detection techniques. ${ }^{10}$ ILs have a long history in the field of electrochemistry ${ }^{11}$ with more recent examples in electro-nanomaterial technologies. ${ }^{12}$ Active pharmaceutical ingredients (APIs) have been re-formulated as ionic liquids themselves ${ }^{13}$ to overcome difficulties with solidstate polymorphic forms and other processing challenges, etc.

Despite all of the numerous chemistries and applications possible, reports of the synthesis of ionic liquids often include the very solvents that they will purportedly replace. Solvents such

Department of Chemical and Petroleum Engineering, Department of Chemistry, and NSF-ERC Center for Environmentally Beneficial Catalysis, University of Kansas, Lawrence, KS 66045, USA.

E-mail: ascurto@ku.edu; Fax: +1 (785) 864 4967; Tel: +1 (785) 864 4947

$\dagger$ Current address: GE, Inc., 1233 West Loop South, Houston, TX 77027, USA as dichloromethane, 1,1,1-trichloroethane, petroleum ether, toluene, etc. have all been used in their synthesis. ${ }^{14-18}$ Moreover, ILs are often too costly to be utilized as an alternative solvent in many large-scale industrial processes. ${ }^{19}$ This is primarily due to small batch production and nearly non-existent kinetic and thermodynamic data of their synthesis that has resulted in little emphasis on reaction engineering and process intensification in the literature. For ionic liquids to be truly "green" and to be used ubiquitously, they must be made in a corresponding benign way in potentially large quantities and for low cost.

\subsection{Reactions: solvent or solvent-less?}

Is a solvent necessary for the synthesis of ionic liquids? Would not a neat reaction be preferred over even an environmentallybenign solvent? Typically, quaternization reactions are highly exothermic reactions. It has been reported that the heat of reaction for 1-methylimidazole and 1-bromobutane is $-96 \mathrm{~kJ} \mathrm{~mol}^{-1}$ by Waterkamp et al. ${ }^{20}$ They estimated the adiabatic temperature for a run-away reaction for this system to be $48{ }^{\circ} \mathrm{C}$ and greater. ${ }^{20}$ This amount of heat release can cause a number of safety concerns along with poor quality product. Burrell et al. ${ }^{21}$ investigated synthesis of larger scale quantities $(\sim 1 \mathrm{~kg})$ of ILs and warn: "Caution: [this] reaction is exothermic and cooling is advisable for large scale reactions". In a controlled experiment in our laboratory, when $200 \mathrm{~mL}$ of 1-methylimidazole were mixed at room temperature with $200 \mathrm{~mL}$ of 1-bromoethane in a $500 \mathrm{~mL}$ round-bottom flask, the mixture began to overboil within approximately 15 minutes. However, a solvent would help dissipate and manage much of the heat generated on both a laboratory scale and larger. 
In addition, many ILs or their intermediates can often be quite viscous. $^{22,23}$ Thus, as the reaction proceeds, uniform mixing for heat and mass transport issues may become a concern. ${ }^{24}$ By using solvents, the viscosity can be kept relatively low. ${ }^{25}$ Moreover, some ILs or their intermediates are actually higher meltingpoint solids, which would require much different processing techniques than for liquid solutions. For instance, the liquidphase reaction between 1-methylimidazole and 1-bromoethane, mentioned above for its exothermicity, forms a solid compound at room-temperature and melts to a viscous liquid at $76{ }^{\circ} \mathrm{C} .{ }^{26}$ By using a solvent, the product can be kept in a relatively lowviscosity liquid solution that can be more easily processed. As will be shown in the following sections, the reaction kinetics can actually be faster in some solvents than in the neat reaction.

\subsection{Overview}

The current study quantitatively examines the solvent effects on the kinetics in the synthesis of a model ionic liquid, 1-hexyl-3-methylimidazolium bromide [HMIm] $[\mathrm{Br}]$ in a wide variety of conventional and low-toxicity organic solvents. This contribution will demonstrate that safer/more-benign solvents can be utilized for producing ILs, while maintaining a high rate of reaction. Solvent selection was determined by understanding the effect of polarity on the kinetic rate constant through correlation with Kamlet Taft $(K T)$ polarity parameters ${ }^{27}$ in a Linear Solvation Energy Relationship (LSER). These correlations, along with solvent toxicity and environmental impact data, then enabled the rapid optimization of solvents for both productivity and low impact. These results will allow larger-scale production of ILs, which will ultimately decrease their cost.

\section{Background}

\subsection{Ionic liquid synthesis}

ILs are most commonly synthesized by a quaternization reaction of a substituted amine (or phosphine, $N$-heterocycles, etc.) with alkyl halides ${ }^{28-32}$ (see Fig. 1), which is followed by anion exchange if necessary. Throughout the quaternization reaction, two neutral reactants form oppositely charged ions through a polar transition state. The rate of reaction is influenced heavily by the "polarity" of the reaction mixture or solvent. ${ }^{33,34}$ This was first demonstrated by Menshutkin over a century ago while studying nucleophilic substitution reactions $\left(\mathrm{S}_{\mathrm{N}} 2\right)$ between amines with haloalkanes in 23 solvents. ${ }^{27,35}$ As will be discussed below, solvent "polarity" can be further described by several different features. Over the past century, a large number of studies have been performed examining the solvent effects on the transition state in the formation of ionic compounds. This investigation will illustrate the large difference in reaction kinetics in different solvents for the synthesis of 1-alkyl-3methyl-imidazolium ionic salts and liquids.

\subsection{IL process development}

From the literature, only a few studies have examined reaction engineering or process intensification for the production of ILs. The issue of heat removal from a neat reaction may be aided by proper reactor engineering solutions. For instance, Waterkamp et al. ${ }^{20}$ have used micro-reactors to produce 1-butyl3-methyl-imidazolium bromide, as micro-reactors have high surface area for heat removal. Minnich et al. ${ }^{36}$ investigated the kinetics of producing 1-ethyl-3-methylimidazolium ethylsulfate for use in micro-reactors. However, micro-reactors can only be used for liquids and require adequate pumping for the high-viscosity liquefied product. Varma and Namboodiri ${ }^{37}$ and Deetlefs and Seddon ${ }^{38}$ have shown that ILs can be synthesized more rapidly using microwave radiation which decreases the relative reaction times. Leveque et al. ${ }^{39}$ have found that ultrasonic irradiation is a useful tool for making a large number of ILs in a one-pot synthesis method. Grosse-Böwing and Jess have reported the bimolecular kinetic constants for the production of 1-butyl-3-methyl-imidazolium chloride. ${ }^{40}$ Recently, they have described some of the important reactor engineering properties for the neat synthesis of 1-ethyl-3-methyl-imidazolium ethylsulfate ionic liquids. ${ }^{41}$

\section{3. "Green"/sustainable solvent selection}

Many factors are involved in the selection of an "appropriate" solvent ${ }^{42}$ for syntheses based upon principles of "green"/sustainable chemistry and engineering. ${ }^{43,44}$ For the production of any chemical, high kinetic rates are preferred. Facile and low-energy separations are needed to purify the ionic liquid. The human and environmental impact, especially of the solvent, is an important aspect in designing safer and more sustainable processes. However, as will be shown below, some of the more benign solvents may yield slow reaction rates and energy-intensive separations processes. Thus, a balance must be made between the inherent toxicity for a given solvent with the desired rates of reaction to produce ILs, and any subsequent processing. Life-cycle assessment (LCA $)^{45-47}$ is a methodology to determine the effect of various process parameters on the required energy, environmental impact, and profitability for the process from cradle-to-grave. Kralisch et al. ${ }^{48,49}$ employed a modified LCA to analyze the synthesis of several ionic liquids and catalytic processes in them, based upon preliminary or estimated data. For instance, the energy inputs to create the starting materials for imidazolium based ILs are larger than for pyridinium and quaternary ammonium ILs. Increasing the temperature of the synthesis initially decreases the overall impact, but reaches a minimum below $100{ }^{\circ} \mathrm{C}$. While all of the aforementioned aspects of sustainable processes are important, this contribution will focus on the solvents of ionic liquid synthesis, efficiency of the reaction kinetics, and address the issue of separations.

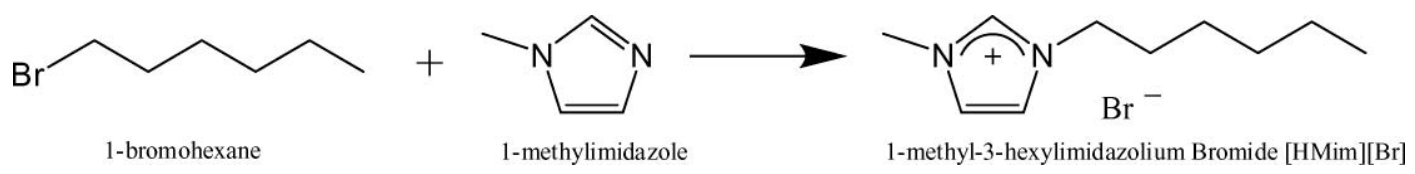

Fig. 1 Reaction between 1-methylimidazole and 1-bromohexane forming 1-hexyl-3-methylimidazolium bromide [HMIm][Br]. 
There are many different ways that solvents can be classified as to their effect on humans and the environment. The US Food and Drug Administration (FDA) typically uses a system of three classes: 1 through 3; in addition to Generally-Regarded-as-Safe (GRAS) solvents. ${ }^{50-52}$ Under these guidelines any Class 1 solvent shall not be used in the production of pharmaceuticals as they are known or suspected human carcinogens. Class 2 solvents have been deemed toxic and should be limited in the production of pharmaceuticals. However, the effects from exposure are reversible and acceptable limits have been established (permitted daily exposure (PDE)). Class 3 solvents are accepted in the production of pharmaceuticals and have low toxicity. GRAS solvents are preferred solvents, which are accepted in the production of pharmaceuticals, and some have been deemed safe as food additives.

While the FDA guidelines are a good indication of human toxicity, they do not include aspects of environmental impact such as aquatic toxicity, smog emissions, biodegradation potential, global warming potential, etc. In addition, the weighting of these different measures of toxicity and environmental impact is also an important issue. One method which takes a large number of health and environmental concerns into consideration is the Rowan Solvent Selection Table (RSST). ${ }^{53,54}$ Originally, the various indicators were weighted to yield an objective function, called the Pharmaceutical Index, which combines human toxicity indices, i.e. ingestion, inhalation, and carcinogen toxicities, with environmental effects, e.g. aquatic toxicity, soil absorption, ozone depletion, smog formation, etc. While the weighting of these different parameters can be discussed, debated and modified, the results do give a good indication of the relative effect on people and the environment. The RSST will be used extensively in this study.

Another useful guide for determining solvent selection is the GlaxoSmithKline (GSK) solvent selection table, which is based on the "International Conference on Harmonization of Technical Requirements for Registration of Pharmaceuticals for Human Use" (ICH guidelines). ${ }^{55}$ In this solvent selection table there are nine assessments which are examined for solvent selection, and include: incineration, recyclability, volatile organic compounds (VOC's), bio-treatment, environmental impact on air, environmental impact of water, health hazards, exposure potential, and safety hazards. ${ }^{55}$ Each assessment is equally weighed in the ranking of solvents.

While the solvents with the lowest impact on humans and the environment could be chosen at the outset, the kinetics of the synthesis and subsequent separations may actually result in a much worse net effect. In order to expedite solvent screening, a method has been utilized here to correlate and predict solvent performance (kinetics) based upon linear solvation energy relationship (LSER) regression using Kamlet Taft $(K T)$ parameters for the individual solvents.

\subsection{Kamlet Taft polarity scales and LSER}

Rates of reaction in the production of ionic liquids are highly dependent on the solvent media. A method to quantitatively correlate and predict the kinetics based upon the properties of the solvent, such as polarity, would be highly useful. The term "polarity" embodies a number of different concepts, including dipole moment, dielectric constant, hydrogen bond accepting ability, polarizability, etc. While one-parameter scales for polarity, such as the $E_{T}(30) \mathrm{scale}^{27,56,57}$ can approximate qualitative trends, they often cannot be used to quantitatively correlate reaction rates. Kamlet Taft $(K T)$ parameters differentiate various aspects of "polarity", viz. acidity $(\alpha)$, basicity $(\beta)$, and dipolarity/polarizability $\left(\pi^{*}\right)$. Acidity, $\alpha$, is a measure of the solvent's ability to donate a proton in a solvent-to-solute hydrogen bond, ${ }^{58} \beta$ is the measure of the solvent's ability to accept a proton in a solvent-to-solute hydrogen bond, ${ }^{59}$ and $\pi^{*}$ is a measure of the solvent's ability to stabilize a charge or dipole. $^{60,61}$ The $K T$ parameters of the solvent can be used to correlate and predict kinetic rate constants in different solvents using a Linear Solvation Energy Relationship (LSER). The LSER method regresses parameters to correlate the kinetic rate constants, $k$, with the solvent-dependent physicochemical properties: $\alpha, \beta$, and $\pi^{* .27}$

$$
\ln k=\ln k^{0}+a \alpha+b \beta+p\left(\pi^{*}-d \delta\right)
$$

The regressed coefficients, $a, b, p$, and $d$ will indicate the magnitude and direction (positive or negative) the polarity parameter contributes to the kinetic rate. $\delta$ is the polarizability correction term which is equal to 0.0 for non-chlorinated solvents, 0.5 for polychlorinated solvents, and 1.0 for aromatic solvents. ${ }^{62}$

\section{Results and discussion}

\subsection{Solvent effects on kinetics}

Initially, this study focused on five traditional organic solvents for the reaction of 1-methylimidazole with 1-bromohexane to form the ionic liquid [HMIm][Br]. The initial solvents (acetonitrile, acetone, methanol, dichloromethane, and chlorobenzene) have a wide range of polarity and different levels of toxicity and environmental impact factors that will be discussed below. For each reaction, the mole ratio of reactants to solvent was maintained at $1: 1: 20$ to avoid concentration effects on the bulk polarity from the reactant and/or product. Each reaction was conducted at three different temperatures: $25{ }^{\circ} \mathrm{C}, 40{ }^{\circ} \mathrm{C}$, and $60{ }^{\circ} \mathrm{C}$, yielding insight to the transition state and activation parameters. For the chlorobenzene system, the mixture splits into two phases (IL-rich and reactant/solvent-rich) after $\sim 6 \%$ conversion. While the developing reaction may occur in either phase, 1-bromohexane is relatively insoluble (immiscible) in the ionic liquid. Thus, little reaction is believed to occur in the IL phase and the overall rate reported here is also the rate in the solvent phase. The change of concentration with time for the synthesis of [HMIm] [Br] in acetonitrile at $40{ }^{\circ} \mathrm{C}$ is shown in Fig. 3 as an example. All rates of reaction at $40^{\circ} \mathrm{C}$ were regressed non-linearly assuming 2 nd order kinetics and are presented in Table 1, along with the $K T$ parameters and $E_{T}(30)$ values; for reference, the $K T$ parameters of the reactants and IL product are also given. It was anticipated from the well-known work of Menshutkin ${ }^{35}$ and general $\mathrm{S}_{\mathrm{N}} 2$ reactions that the kinetic rate would increase with increasing polarity. From the five initial solvents, the rate of reaction is the greatest in acetonitrile, and is more than one order of magnitude higher than that of methanol. Methanol was the slowest despite being considered one of the 
Table 1 Rate constants at $40{ }^{\circ} \mathrm{C}, K T$ parameters and $E_{T}(30)$ values for all solvents examined ${ }^{a}$

\begin{tabular}{|c|c|c|c|c|c|}
\hline Solvent & $\frac{k \times 10^{6} / \mathrm{M}^{-1} \mathrm{~s}^{-1}}{40^{\circ} \mathrm{C}}$ & \multicolumn{3}{|c|}{ Kamlet Taft parameters } & $E_{T}(30) / \mathrm{kcal} \mathrm{mol}^{-1}$ \\
\hline Acetonitrile & $21.56 \pm 0.21$ & $0.230 \pm 0.009$ & $0.376 \pm 0.012$ & $0.787 \pm 0.012$ & $45.62 \pm 0.02$ \\
\hline Cyclopentanone & $15.11 \pm 0.11$ & $-0.085 \pm 0.005$ & $0.565 \pm 0.004$ & $0.748 \pm 0.003$ & $39.85 \pm 0.01$ \\
\hline Acetone & $12.67 \pm 0.06$ & $0.110 \pm 0.002$ & $0.523 \pm 0.012$ & $0.715 \pm 0.002$ & $42.58 \pm 0.03$ \\
\hline 2-Butanone & $11.56 \pm 0.08$ & $0.053 \pm 0.004$ & $0.568 \pm 0.004$ & $0.675 \pm 0.002$ & $41.06 \pm 0.06$ \\
\hline Chlorobenzene $^{b}$ & $3.64 \pm 0.11^{b}$ & $0.051 \pm 0.004$ & $0.080 \pm 0.009$ & $0.624 \pm 0.004$ & $36.91 \pm 0.02$ \\
\hline Ethyl lactate & $2.86 \pm 0.06$ & $0.642 \pm 0.004$ & $0.633 \pm 0.010$ & $0.689 \pm 0.002$ & $51.01 \pm 0.04$ \\
\hline Methanol & $2.03 \pm 0.08$ & $0.909 \pm 0.006$ & $0.629 \pm 0.009$ & $0.697 \pm 0.006$ & $55.53 \pm 0.04$ \\
\hline 1-Methylimidazole & - & $0.232 \pm 0.012$ & $0.712 \pm 0.016$ & $0.961 \pm 0.014$ & $44.85 \pm 0.01$ \\
\hline 1-Bromohexane & - & $0.014 \pm 0.07$ & $-0.009 \pm 0.011$ & $0.500 \pm 0.01$ & $37.9 \pm 0.70$ \\
\hline [HMIm][Br] & - & $0.453 \pm 0.069$ & $0.562 \pm 0.066$ & $0.983 \pm 0.037$ & $50.49 \pm 0.18$ \\
\hline
\end{tabular}

${ }^{a}$ All rates of reaction at $40{ }^{\circ} \mathrm{C}$ were conducted at a $1: 1: 20$ mole ratio (1-methylimidazole : 1-bromohexane : solvent). ${ }^{b}$ Mixture split into two phases during reaction and the reported kinetic constants assume that the reaction does not occur in the IL-rich phase due to poor solubility of 1-bromohexane.

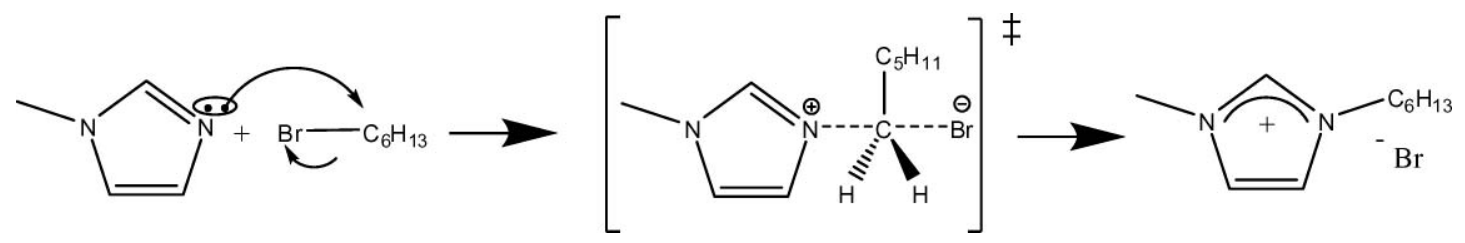

Fig. 2 Transition state for the reaction between 1-methylimidazole and 1-bromohexane.

most "polar." Thus, simple heuristics of increasing polarity to increase kinetic rate is not always qualitatively valid. The reaction in acetonitrile is even greater than in the neat reaction without solvent. The natural $\log$ of $k$ was fit to the LSER coefficients based on the $K T$ parameters (acidity $\alpha$, basicity $\beta$, and dipolarizability $\left.\pi^{*}\right)$ :

$$
\begin{gathered}
\ln k=-62.08-3.79 \alpha+20.89 \beta+56.36\left(\pi^{*}-0.23 \delta\right) \\
R^{2}=0.99
\end{gathered}
$$

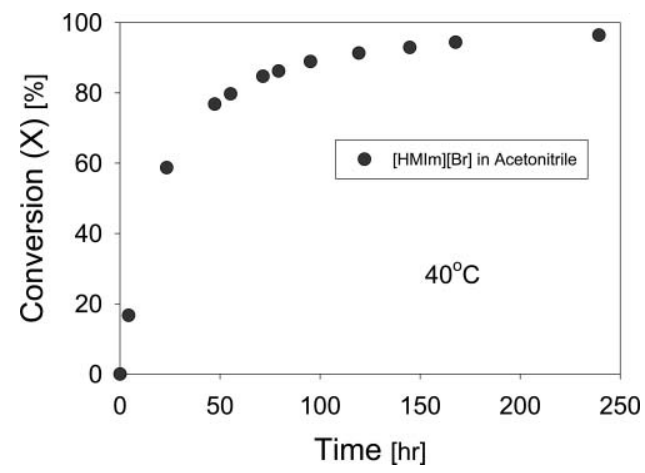

Fig. 3 Concentration versus time for the formation of [HMIm] [Br] in acetonitrile at $40{ }^{\circ} \mathrm{C}$.

From the regression it is seen that the $\pi^{*}$ parameter (dipolarity/polarizability) has the largest positive effect on the reaction rate, followed by the $\beta$ parameter (basicity). The $\alpha$ parameter (acidity) has a negative effect on the rate of reaction. This relationship of 5 solvents with a wide variety of polarity then allows us to optimize the rate at least qualitatively: solvents with large $\beta$ and $\pi^{*}$ and a small $\alpha$ should be chosen, i.e. high dipolarity and hydrogen bond acceptor/electron donor capability, and small hydrogen bond donating/electron accepting ability.

The general effects of polarity on the synthesis of imidazolium based ILs as determined from the solvent subset can now be used to aid the choice of other solvents with lower toxicity and environmental impact. From eqn (2) and $K T$ parameters, five additional solvents were selected among Class 3 and GRAS solvents: ethyl formate, ethyl lactate (also a bio-renewable solvent ${ }^{63,64}$ ), dimethyl sulfoxide, 2-butanone, and cyclopentanone. The results for the 10 solvents are presented in Table 1 along with the experimentally measured $K T$ and $E_{T}(30)$ parameters. A majority of the new solvents did not have a complete set of parameters based on one set of solvatochromic probes.

A single parameter correlation for all ten solvents using the $E_{T}(30)$ scale is inadequate at qualitative and quantitative correlation, as shown in Fig. 4 . The $E_{T}(30)$ scale only embodies one aspect of polarity important in this reaction. This result was also seen by Abraham et al. ${ }^{65}$ who worked with a trimethylamine/ $p$-nitrobenzyl chloride system. A similar conclusion was obtained by Skrzypczak and $\mathrm{Neta}^{34}$ studying the reaction of 1,2-dimethylimidazole and benzylbromide.

The LSER analysis, now for all 10 solvents, was regressed against the kinetic rate constant:

$\ln k=-14.72-2.07 \alpha+0.07 \beta+4.99\left(\pi^{*}-0.20 \delta\right) R^{2}=0.95$

and the results are given in Fig. 5. The rates of reactions are heavily influenced by the solvent choice, and can be predicted fairly accurately using $K T$ parameters in a LSER regression. This phenomena can qualitatively be explained by the solvation 


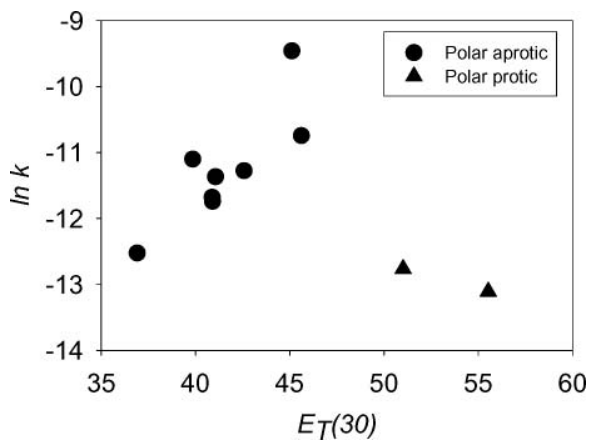

Fig. 4 Correlation of kinetic constant, $k$, with the $E_{T}(30)$ polarity scale for all solvents examined.

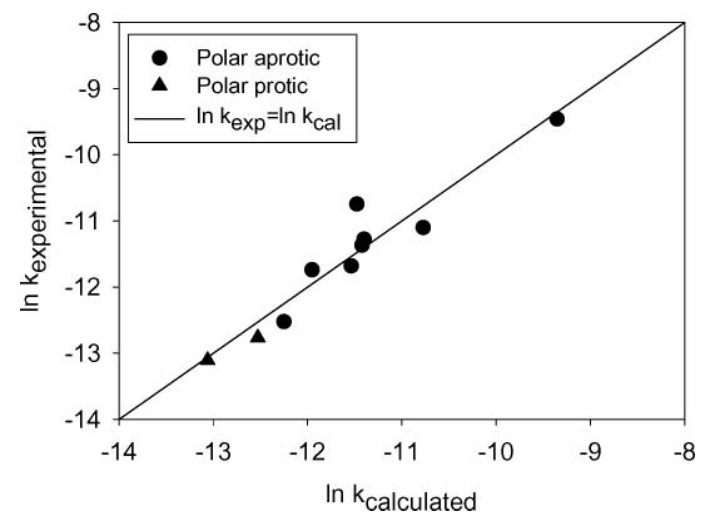

Fig. 5 LSER (eqn (7)) results for the 10 solvents used in this study at $40{ }^{\circ} \mathrm{C}$.

scheme of Hughes and Ingold..$^{27,66-68}$ For the alkylation of 1-methylimidazole with haloalkanes, two neutral reactants form a transition state of significant charge separation, followed by full charge separation in the product cation and anion (Fig. 2). As seen in Table 1 for the polar aprotic solvents, an increase in the solvent polarity ( $\pi^{*}$ and $E_{T}(30)$ ) results in an increase in the rate of reaction. Following Hughes and Ingold's ${ }^{66,68}$ interpretation, the reaction is dominated by the degree of charge existing at the transition state. Solvents with higher dipolarity and basic character can stabilize better the charged transition state. However, polar protic solvents retard the reaction rate despite their high dipolarity. They form hydrogen bonds with the lone pair of electrons on the nitrogen of 1-methylimidazole, thus inhibiting nucleophilic attack on the haloalkane.

These effect of polarity on the kinetics may also be viewed by analysis of the Arrhenius ${ }^{69}$ and Eyring ${ }^{70,71}$ parameters. The Eyring equation is given by:

$$
k=\frac{k_{\mathrm{B}} T}{h} \exp ^{\left(-\frac{\Delta H^{\ddagger}}{R T}\right)} \exp ^{\left(\frac{\Delta S^{\ddagger}}{R}\right)}
$$

where $k_{\mathrm{B}}$ is the Boltzmann's constant, $T$ is temperature, $h$ is the Plank's constant, $R$ is the gas rate constant, $\Delta H^{\ddagger}$ is the enthalpy of activation, and $\Delta S^{*}$ is the entropy of activation.

The Arrhenius equation is given by:

$$
k=k_{0} \exp ^{\left(-\frac{E_{\mathrm{a}}}{R T}\right)}
$$

where $E_{\mathrm{a}}$ is the activation energy and $k_{0}$ is the pre-exponential term.

Table 2 summarizes the parameters for each of the models determined from the kinetic constants at $25{ }^{\circ} \mathrm{C}, 40{ }^{\circ} \mathrm{C}$, and $60{ }^{\circ} \mathrm{C}$, unless otherwise specified. The values for $\Delta H^{\ddagger}$ are similar between the two major solvent types: polar aprotic solvents and

\begin{tabular}{|c|c|c|c|c|c|c|c|}
\hline \multirow[b]{2}{*}{ Solvent } & \multicolumn{3}{|c|}{$k \times 10^{6} / \mathrm{M}^{-1} \mathrm{~s}^{-1}$} & \multirow[b]{2}{*}{$k_{0} \times 10^{-6} / \mathrm{M}^{-1} \mathrm{~s}^{-1}$} & \multirow[b]{2}{*}{$E_{\mathrm{a}} / \mathrm{kJ} \mathrm{mol}^{-1}$} & \multirow[b]{2}{*}{$\Delta H^{\ddagger} / \mathrm{kJ} \mathrm{mol}^{-1}$} & \multirow[b]{2}{*}{$\Delta S^{\ddagger} / \mathrm{J} \mathrm{mol}^{-1} \mathrm{~K}^{-1}$} \\
\hline & $25^{\circ} \mathrm{C}$ & $40^{\circ} \mathrm{C}$ & $60^{\circ} \mathrm{C}$ & & & & \\
\hline DMSO & $22.22 \pm 0.11$ & $77.89 \pm 1.72$ & $322.31 \pm 3.53^{a}$ & 2.51 & 63.05 & 60.43 & -131.19 \\
\hline Acetonitrile & $6.03 \pm 0.14$ & $21.56 \pm 0.21$ & $110.64 \pm 1.42$ & 6.51 & 68.73 & 66.11 & -123.26 \\
\hline Cyclopentanone & $3.75 \pm 0.03$ & $15.11 \pm 0.11$ & $76.11 \pm 1.72$ & 10.4 & 71.00 & 68.38 & -119.37 \\
\hline Acetone & $3.69 \pm 0.17$ & $12.67 \pm 0.06$ & $63.67 \pm 0.61$ & 2.20 & 67.26 & 64.64 & -132.30 \\
\hline 2-Butanone & $2.69 \pm 0.03$ & $11.56 \pm 0.08$ & $53.75 \pm 0.28$ & 6.25 & 70.50 & 67.88 & -123.60 \\
\hline Dichloromethane & $2.28 \pm 0.11$ & $8.47 \pm 0.11$ & $-^{b}$ & 1.85 & 67.98 & 65.44 & -133.45 \\
\hline Ethyl formate & $1.61 \pm 0.03$ & $7.97 \pm 0.14$ & $-^{b}$ & 507 & 82.75 & 80.21 & -86.78 \\
\hline Chlorobenzene $^{c}$ & $1.11 \pm 0.06$ & $3.64 \pm 0.11$ & $24.64 \pm 1.39$ & 7.51 & 73.43 & 70.81 & -122.07 \\
\hline Ethyl lactate & $0.53 \pm 0.03$ & $2.86 \pm 0.06$ & $20.28 \pm 0.28$ & 636 & 86.05 & 83.43 & -85.18 \\
\hline Methanol & $0.42 \pm 0.03$ & $2.03 \pm 0.08$ & $17.14 \pm 0.11$ & 987 & 87.85 & 85.24 & -81.52 \\
\hline $\mathrm{Neat}^{c, d}$ & $4.53 \pm 0.04$ & $17.63 \pm 0.06$ & $106.34 \pm 13.2$ & 51.2 & 74.57 & 71.95 & -106.12 \\
\hline
\end{tabular}

Table 2 Rates of reaction and kinetic parameters

${ }^{a}$ Reaction conducted at $1: 1: 80$ mole ratio 1-methylimidazole : 1-bromohexane : dimethyl sulfoxide due to high exothermicity of more concentrated solutions. ${ }^{b}$ Exceeds boiling point of solvent. ${ }^{c}$ Mixture split into two phases during reaction and the reported kinetic constants assume that the reaction does not occur in the IL-rich phase due to poor solubility of 1 -bromohexane. ${ }^{d} 1$-methylimidazole $: 1$-bromohexane $=1: 1$ by mole.

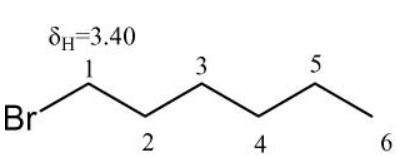

1-bromohexane

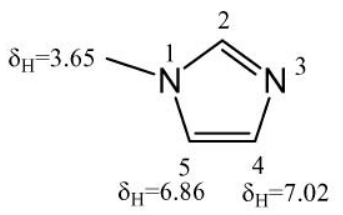

1-methylimidazole

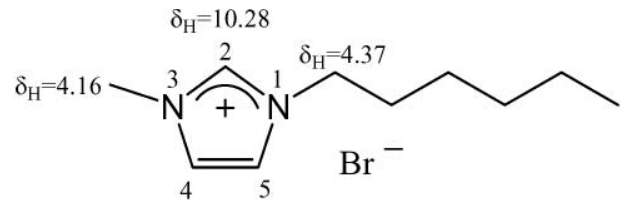

1-methyl-3-hexylimidazolium Bromide [HMim][Br]

Fig. $6 \quad{ }^{1} \mathrm{H}$ NMR chemical shifts for reactants and product. 
polar protic solvents (methanol, ethyl lactate). The values of $\Delta H^{\ddagger}$ for the polar protic solvents are approximately $20 \mathrm{~kJ} \mathrm{~mol}^{-1}$ greater than the polar aprotic solvents. The kinetic parameters in ethyl formate (EF) are similar to those of the polar protic solvents, despite EF having a low acidity ( $\alpha$ parameter). Ethyl formate is susceptible to water, base, acid, and salt catalyzed hydrolysis and decomposition ${ }^{72-76}$ to products with higher $\alpha$ values, such as ethanol, formic acid, etc. Haberfield et al. ${ }^{77}$ suggest, for general $\mathrm{S}_{\mathrm{N}} 2$ reactions, that the difference between the $\Delta H^{\ddagger}$ for protic solvents may be due to stabilization of the reactants relative to aprotic solvents, thus increasing the energy difference between the reactants and the transition state. Additional energy would be needed to break the hydrogen bonds between the solvent and 1-methylimidazole in order for the reaction to occur. Hydrogen bond strengths can vary between $2-20 \mathrm{~kJ} \mathrm{~mol}^{-1},{ }^{78}$ which is of the same order as the difference in $\Delta H^{\ddagger}$ between the polar protic and aprotic solvent classes. Moreover, the $\Delta S^{*}$ for the polar protic solvents is approximately $40 \mathrm{~J} \mathrm{~mol}^{-1} \mathrm{~K}^{-1}$ more (less negative) than the polar aprotic solvents. Hydrogen bonding between the 1-methylimidazole and the solvent would induce a more-ordered ground state, i.e. lower entropy. Thus, the degree of order in the transition state is closer to the ground state with protic solvents.

The current example uses 1-bromohexane as the alkylation agent. Many applications with ionic liquids, e.g. catalysis, are adversely affected by the presence of halide and its removal after anion-exchange is often tedious. As such, several alternative halide-free alkylation techniques have emerged. Bonhôte et al. ${ }^{79}$ have used ethyl triflate and ethyl trifluoroacetates for the alkylation of 1-methylimidazole. Ue et al. ${ }^{80}$ have used the alkylation of 1-ethylimidazole with dimethyl carbonate. Lectercq et al. $^{81}$ have used a complex mechanism involving the reaction between tetrahydrofuran or 1,4-dioxane, with triflic anhydride to form a diester that is then reacted with an $\mathrm{N}$-substituted imidazole. Holbrey et al. ${ }^{16}$ used an alkylation technique between dimethyl sulfate or diethyl sulfate with $\mathrm{N}$-substituted imidazole to form imidazolium alkyl sulfate ILs. Yoshizawa et al. ${ }^{82}$ have synthesized a number of zwitterionic type ILs by reacting imidazoles with 1,3-propanesultone. The kinetic rates and effects of solvents of several of these alternative alkylations are under investigation.

\subsection{Diffusion limited kinetic constant}

The diffusion-limited rate constant was calculated for comparison to the intrinsic kinetic rate constants. The binary diffusion coefficients for 1-methylimidazole and 1-bromohexane in dimethyl sulfoxide (DMSO) have been determined at $25{ }^{\circ} \mathrm{C}$ in another study in our laboratory ${ }^{83}$ and is illustrated in Table 3. DMSO was chosen as a model solvent as it simultaneously produces the largest kinetic rate of synthesis and is the most viscous solvent studied. Thus, the reaction in DMSO should be the nearest to the diffusional limited regime. As shown in the table, 1-methylimidazole diffuses slightly faster than 1-bromohexane.

The analysis for the diffusion-limited rate constant for a reaction in a homogeneous medium is given by: ${ }^{78}$

$$
k_{\mathrm{d}}=4 \pi R^{*} D N_{\mathrm{A}}
$$

Table 3 Calculating the $k_{\mathrm{d}}$ in DMSO for the reaction between 1-methylimidazole and 1-bromohexane

\begin{tabular}{lcl}
\hline$D_{\mathrm{a}}(1 \text {-methylimidazole })^{a}$ & $6.10 \times 10^{-10}$ & \\
$D_{\mathrm{b}}(1 \text {-bromohexane })^{a}$ & $5.90 \times 10^{-10}$ & $\mathrm{~m}^{2} \mathrm{~s}^{-1}$ \\
$D=\left(D_{\mathrm{a}}+D_{\mathrm{b}}\right)$ & $1.20 \times 10^{-9}$ & $\mathrm{~m}^{2} \mathrm{~s}^{-1}$ \\
${\text { Viscosity }(\mathrm{DMSO})^{b}}_{R_{\mathrm{a}}}$ & $1.987 \times 10^{-3}$ & $\mathrm{~kg} \mathrm{~m}^{-1} \mathrm{~s}^{-1}$ \\
$R_{\mathrm{b}}$ & $1.80 \times 10^{-10}$ & $\mathrm{~m}$ \\
$R^{*}=\left(R_{\mathrm{a}}+R_{\mathrm{b}}\right) / 2$ & $1.86 \times 10^{-10}$ & $\mathrm{~m}$ \\
$k_{\mathrm{d}}$ & $1.83 \times 10^{-10}$ & $\mathrm{~m}$ \\
$k\left(\right.$ at $\left.25^{\circ} \mathrm{C}\right)$ & $1.66 \times 10^{9}$ & $\mathrm{M}^{-1} \mathrm{~s}^{-1}$ \\
& $2.22 \times 10^{-5}$ & $\mathrm{M}^{-1} \mathrm{~s}^{-1}$
\end{tabular}

${ }^{a} D_{\mathrm{a}}$ and $D_{\mathrm{b}}$ are binary diffusion coefficients in DMSO at $25^{\circ} \mathrm{C}$ from ref. 83. ${ }^{b}$ Taken from ref. 92.

where $k_{\mathrm{d}}$ is the diffusion-controlled rate constant, $R^{*}$ is the distance at which the reaction occurs (assumed to be the average distance between the reactants hydrodynamic radii), $D$ is the sum of the reactants diffusion coefficients at the concentration of the reaction, and $N_{\mathrm{A}}$ is Avogadro's constant. Using the StokesEinstein equation, the hydrodynamic radii for each molecule can be calculated by: ${ }^{78}$

$$
R_{\mathrm{a}}=\frac{k_{\mathrm{B}} T}{6 \pi \eta D_{\mathrm{a}}} \text { and } R_{\mathrm{b}}=\frac{k_{\mathrm{B}} T}{6 \pi \eta D_{\mathrm{b}}}
$$

where $R_{\mathrm{a}}$ and $R_{\mathrm{b}}$ are the hydrodynamic radii, $k_{\mathrm{B}}$ is the Boltzmann constant, $T$ is the temperature in $\mathrm{K}, \eta$ is the viscosity of the media, and $D_{\mathrm{a}}$ and $D_{\mathrm{b}}$ are the diffusion coefficient for each species in the solvent media. The equations above assume a hard sphere model for the hydrodynamic radius and yield an approximation of the relative rate in a diffusion-limited regime. The viscosity of the media is assumed to be the viscosity of pure DMSO and the diffusion coefficient in dilute conditions is assumed to representative of the actual reaction. Details of the analysis are given in Table 3 . The kinetic constant in a diffusion-controlled regime, $k_{\mathrm{d}}$, is estimated to be $1.66 \times 10^{9} \mathrm{M}^{-1} \mathrm{~s}^{-1}$, which is 14 orders of magnitude greater than the reported intrinsic rate constant. The speed of these $S_{N} 2$ reactions requires more than just the reactants coming into proximity as suggested by the solvent effects discussed above. As expected, the kinetics rates reported here truly reflect the intrinsic kinetics and indicate that methods to increase mass transfer within the solution, such as stirring, etc., are more important for heat transfer issues than mass transfer.

\subsection{Green/sustainable solvent selection}

Table 4 lists the solvents in order of decreasing rate of reaction for 1-bromohexane with 1-methylimidazole (DMSO is the fastest and methanol the slowest). For solvents that have not been examined in the Rowan Solvent Table, the closest related solvent was used: methyl formate for ethyl formate, methyl lactate for ethyl lactate, cyclohexanone for cyclopentanone, and $o$-dichlorobenzene for chlorobenzene. According to the index, the top 5 most benign solvents of the 10 studied are: DMSO $>$ methyl(ethyl) lactate $>$ acetone $>$ methanol $>$ methyl (ethyl) formate. The GSK solvent selection guide yielded similar conclusions with the top 3 benign solvent choices being: DMSO > acetone $>$ methanol. However, the best solvents for the highest kinetic rates are: DMSO > acetonitrile $>$ cyclopentanone $>$ acetone $>$ 2-butanone. On first inspection, DMSO may seem 
Table 4 Abbreviated results adapted from the RSST for determining the pharmaceutical index

\begin{tabular}{|c|c|c|c|c|c|c|c|c|}
\hline Solvent & Index $^{a}$ & $\begin{array}{l}\text { Inhalation } \\
\text { TLV }(\mathrm{ppm})^{b}\end{array}$ & $\begin{array}{l}\text { Ingestion/ } \\
\mathrm{mg} \mathrm{kg}^{-1} \mathrm{rat}^{b}\end{array}$ & $\begin{array}{l}\text { Carcinogen } \\
{[0-5]^{b}}\end{array}$ & $\begin{array}{l}\text { Aquatic/ } \\
\mathrm{mg} \mathrm{L}^{-1} \mathrm{fish}^{b}\end{array}$ & $\begin{array}{l}\text { Soil adsorption } \\
\text { coefficient }^{b}\end{array}$ & $\begin{array}{l}\text { Smog } \\
\text { formation }^{b}\end{array}$ & $\begin{array}{l}\text { Oct/water partitioning } \\
\text { coefficient }^{b}\end{array}$ \\
\hline DMSO & 0.42 & 1000 & 14500 & 0 & 66901 & 0.65 & 0.00 & -1.35 \\
\hline Acetonitrile & 3.21 & 40 & 3800 & 0 & 4111 & 0.65 & 0.00 & -0.34 \\
\hline Cyclohexanone $^{c}$ & 5.37 & 50 & 1800 & 3 & 754 & 1.18 & 0.53 & 0.81 \\
\hline Acetone & 2.15 & 500 & 5800 & 1 & 6967 & 0.30 & 0.18 & -0.24 \\
\hline 2-Butanone & 4.00 & 200 & 2737 & 2 & 3173 & 0.58 & 0.51 & 0.29 \\
\hline Dichloromethane & 5.36 & 50 & 1600 & 3 & 428 & 1.38 & 0.03 & 1.34 \\
\hline Methyl formate ${ }^{c}$ & 3.11 & 100 & 475 & 1 & 6260 & 0.33 & 0.00 & 0.03 \\
\hline Methyl lactate $^{c}$ & 1.57 & 1000 & 2000 & 0 & 29583 & 0.00 & 0.00 & -0.67 \\
\hline Methanol & 2.52 & 200 & 5628 & 0 & 8403 & 0.00 & 0.21 & -0.77 \\
\hline
\end{tabular}

Table 5 Boiling points, latent heats, sensible heats and total energy obtained for energy analysis

\begin{tabular}{|c|c|c|c|c|c|c|}
\hline Solvent & $\begin{array}{l}\text { Molecular } \\
\text { weight } / \mathrm{g} \mathrm{mol}^{-1}\end{array}$ & $\begin{array}{l}\text { Boiling point, } \\
T_{\mathrm{b}} /{ }^{\circ} \mathrm{C}^{a}\end{array}$ & $\begin{array}{l}\Delta H^{\mathrm{vap}}\left(T_{\mathrm{b}}\right)^{a} / \\
\mathrm{kJ} \mathrm{mol}^{-1}\end{array}$ & $\begin{array}{l}C_{p} \text { at } 25^{\circ} \mathrm{C}^{a} / \\
\mathbf{J ~ g}^{-1} \mathrm{~K}^{-1}\end{array}$ & $\begin{array}{l}\text { Sensible heat }{ }^{b} / \\
\mathrm{kJ} \mathrm{mol}^{-1}\end{array}$ & $\begin{array}{l}\text { Total heat/ } \\
\mathrm{kJ} \mathrm{mol}^{-1}\end{array}$ \\
\hline Dimethyl sulfoxide & 78.13 & 189.0 & 43.1 & 1.958 & 22.79 & 65.89 \\
\hline Acetonitrile & 41.05 & 81.7 & 29.75 & 2.229 & 3.84 & 33.59 \\
\hline Cyclopentanone & 98.14 & 130.6 & 36.35 & 1.840 & 16.43 & 52.78 \\
\hline Acetone & 58.08 & 56.1 & 29.1 & 2.175 & 2.06 & 31.16 \\
\hline 2-butanone & 72.1 & 79.6 & 31.3 & 2.201 & 6.35 & 37.65 \\
\hline Dichloromethane & 84.93 & 40.0 & 28.06 & 1.192 & 0.0 & 28.06 \\
\hline Ethyl formate & 74.08 & 54.4 & 29.91 & 2.015 & 2.09 & 32.00 \\
\hline Chlorobenzene & 147.01 & 131.7 & 35.19 & 1.334 & 17.85 & 53.04 \\
\hline Ethyl lactate & 118.13 & 154.5 & $52.5^{c}$ & 2.150 & 28.70 & 81.20 \\
\hline Methanol & 32.04 & 64.6 & 35.21 & 2.531 & 2.00 & 37.21 \\
\hline
\end{tabular}

the ideal solvent to produce [HMIm][Br]: the highest reaction rate and lowest toxicity/environmental impact. However, what is not considered here is the energy to separate the solvent from the IL using distillation/evaporation. Consideration of the boiling point and heat of vaporization may yield a peripheral energy analysis. In actual distillation/evaporation, one would need to consider the phase equilibrium thermodynamics (activity coefficients, etc.) to design the separation train and energy requirements; these are often more than simply the sensible heat and latent heat of vaporization. ${ }^{55}$ Table 5 lists the boiling points, heats of vaporization, sensible heat, and the total energy for the solvents investigated. As seen in Table 5, DMSO's boiling point and heat of vaporization (thus energy requirement) is quite high compared to the other solvents in the table. This excess energy would result in higher energy usage and, thus, more pollution, which in turn would worsen the actual measure of toxicity and environmental impact of the solvent. Based on comparison of the reaction rates, the solvents' Index, and a scan of the energy requirements of separation, acetone appears to possess an optimal combination of properties for use, at least on the bench-scale, if not on an industrial scale. In addition, acetone is relatively inexpensive, can be purchased on a large scale, and can be produced by bio-renewable methods (ABE fermentation) ${ }^{84}$

Other means of separation should also be considered for a complete analysis. These techniques range from liquid extraction to more recent techniques using low to moderate pressure of $\mathrm{CO}_{2}$ to induce phase splitting. ${ }^{85-87} \mathrm{CO}_{2}$ has been found to induce a broad range of IL-solvent mixtures to split into an IL-rich and solvent-rich phase that can be decanted, or, at higher pressures, extracted by near- or supercritical $\mathrm{CO}_{2}$. Scurto ${ }^{88}$ indicates that depending on the needed purity, the energy needed to power a compressor for a $\mathrm{CO}_{2}$ separation process may be competitive with the energy (heat) requirements for evaporation/distillation, even with relatively high volatility solvents such as methanol.

\section{Experimental}

\subsection{Kinetic measurements}

The reaction of 1-methylimidazole and haloalkanes with different solvents was conducted at three different temperatures using a multi-well reactor block from Chemglass, Inc. (model number CG-1991-03) which holds 16 standard $20 \mathrm{~mL}$ scintillation vials. The temperature and stirring of the reactor block was maintained using an IKAMAG RET basic hotplate equipped with an ETS-D4 fuzzy logic temperature controller that maintained the temperature to $\pm 1{ }^{\circ} \mathrm{C}$. Reactants were carefully weighed to $0.01 \mathrm{mg}$ in $20 \mathrm{~mL}$ scintillation vials and a magnetic stir bar was placed in each vial. The vials were then placed in the reactor block and samples were drawn from each vial and placed in NMR tubes containing deuterated chloroform at room temperature. The samples were quickly analyzed using a Bruker $400 \mathrm{MHz}$ Nuclear Magnetic Resonance (NMR) spectrometer. Typically, the time duration between sample extraction and 
NMR analysis was less than 5 minutes; further conversion during this time was negligible due to the relatively slower kinetic rates at ambient conditions, and the more dilute concentrations after adding deuterated chloroform. The conversion over time was determined by following the disappearance of the reactant and appearance of the product peaks on the NMR spectrum.

The methyl peaks for the reactant, 1-methylimidazole and the corresponding methyl peaks for [HMIm] $[\mathrm{Br}]$ at $\delta_{\mathrm{H}} \sim 3.65 \mathrm{ppm}$ and $\delta_{\mathrm{H}} \sim 4.16 \mathrm{ppm}$, respectively (see Fig. 6), are integrated to determine the fractional conversion, $X$, using the following equation:

$$
X=\frac{C_{\mathrm{MIm}}^{0}-C_{\mathrm{MIm}}}{C_{\mathrm{M} I m}^{0}}=\frac{N_{\mathrm{IL}}}{N_{\mathrm{MIm}}^{0}}=\frac{N_{\mathrm{IL}}}{N_{\mathrm{MIm}}+N_{\mathrm{IL}}}=\frac{I_{\delta_{\mathrm{H}} 4.16}}{I_{\delta_{\mathrm{H}} 4.16}+I_{\delta_{\mathrm{H}} 3.65}}
$$

where $N$ is the number of moles of each species at any point in time, $N^{0}$ is initial amounts of limiting reactant, and $I$ is the peak area at each of the chemical shifts being analyzed. Alternatively, the conversion could be determined based on the difference in the methylene peak next to the bromine $\left(\delta_{\mathrm{H}} 3.40 \mathrm{ppm}\right)$ or the imidazolium ring $\left(\delta_{\mathrm{H}} 4.37 \mathrm{ppm}\right)$; see Fig. 6 . When the individual solvent peaks overlap with these peaks in the NMR spectra, the peaks at $\delta_{\mathrm{H}} 7.02 \mathrm{ppm}$ and $\delta_{\mathrm{H}} 10.28 \mathrm{ppm}$ were used for calculating conversion, which correspond to the hydrogen in position number 5 on the 1-methylimidazole and the hydrogen in position number 2 on the [HMIm][Br]; see Fig. 6. For further details of the NMR technique, see Schleicher. ${ }^{89}$ The accuracy of this method to determine $X$ has been estimated to $\pm 1 \%$.

The reaction rates were confirmed to be 2 nd order/ bimolecular according to the expression:

$$
r_{\mathrm{IL}}=-r_{\mathrm{MIm}}=-r_{\mathrm{BrHex}}=-\left(\frac{\partial C_{\mathrm{MIm}}}{\partial t}\right)=k C_{\mathrm{MIm}} C_{\mathrm{BrHex}}
$$

or alternatively: ${ }^{90}$

$$
r_{\mathrm{IL}}=-r_{\mathrm{MIm}}=C_{\mathrm{MIm}}^{0}\left(\frac{\partial X}{\partial t}\right)=k\left(C_{\mathrm{MIm}}^{0}-C_{\mathrm{MIm}}^{0} X\right)\left(C_{\mathrm{BrHex}}^{0}-C_{\mathrm{MIm}}^{0} X\right)
$$

where $r$ is the reaction rate based on component $i, k$ the kinetic constant, $C^{0}{ }_{i}$ the initial concentrations of the components (molarity), and $X$ is the fractional conversion (eqn (8)).

When the initial concentrations of the two reactants are equal (1: 1 stoichiometry), eqn (10) becomes:

$$
\begin{aligned}
& r_{\mathrm{IL}}=-r_{\mathrm{MIm}}=C_{\mathrm{MIm}}^{0}\left(\frac{\partial X}{\partial t}\right)=k\left(C_{\mathrm{MIm}}^{0}\right)^{2}(1-X)^{2} \\
& \frac{X}{C_{\mathrm{M} I m}^{0}(1-X)}=k t
\end{aligned}
$$

While the kinetic constant could be obtained by graphing the experimental data to a linearized form of eqn (11), this often introduces unnecessary errors or undue emphasis on certain time regimes. A non-linear regression technique is used here in the software SigmaPlot 2000.

\subsection{Kamlet Taft measurements}

Many different solvatochromic probes can be used to determine the $K T$ parameters. Different sets of dyes produce slightly different results and, thus, comparison with other studies should be made only with similar dye sets. ${ }^{58-60,91}$ In this study, the solvatochromic probes: $N, N$-diethyl-4-nitroaniline, 4-nitroaniline, and Reichardt's dye, were used to calculate the three solvent parameters $\alpha, \beta$, and $\pi^{*}$. All $K T$ parameters and $E_{T}(30)$ values were obtained from solutions with the appropriate dyes using a Varian Cary 300 Bio Ultra violet-Visible (UV-Vis) Spectrophotometer, with a dual cell Peltier accessory temperature controller. The temperature was maintained at the standard $25{ }^{\circ} \mathrm{C}$. The wavelengths of maximum absorption of the dyes are related to the $K T$ parameters using the standard formulas. ${ }^{27}$ The LSER coefficients were regressed using the non-linear optimization techniques in the software: Sigma-Plot 2000 version 6.0.

\subsection{Materials}

Reagents: 1-methylimidazole (>99\%), 1-chlorohexane (95\%), 1-iodohexane (>98\%), and 1-bromopropane (99\%) were obtained from Acros Organics, while 1-bromohexane (>99\%), 1-bromopentane (99\%), 2-bromopentane (95\%), 1-bromo-3methylbutane (96\%), 2-bromo-2-methylbutane (95\%), and 1bromodecane $(98 \%)$ were obtained from Sigma Aldrich. Solvents: acetonitrile $(>99.9 \%)$, acetone $(>99.9 \%)$, methanol (>99.9\%), chlorobenzene $(99.9 \%)$, dichloromethane $(99.8 \%)$, dimethyl sulfoxide (>99\%), cyclopentanone (>99\%), ethyl lactate (>98\%), 2-butanone (>99.7\%), and cyclohexane $(>99.9 \%)$ were all obtained from Sigma Aldrich, while ethyl formate (>98\%) was purchased from Acros Organics. Solvatochromic probes: 4-nitroaniline $(>99 \%)$ was purchased from Sigma Aldrich, $N, N$-diethyl-4-nitroaniline (97\%) was purchased from Oakwood Products Inc., and Reichardt's Dye (>90\%) was purchased from Fluka. All starting materials were distilled and kept under argon gas prior to use. All solvents were dried using $3 \AA$ or $4 \AA$ molecular sieves. The solvatochromic probes Reichardt's Dye, 4-nitroaniline, and $N, N$-diethyl-4-nitronaniline were used as received.

\section{Conclusion}

The kinetic rate constants for the reaction of 1-bromohexane with 1-methylimidazole have been determined in 10 solvents at $25{ }^{\circ} \mathrm{C}, 40{ }^{\circ} \mathrm{C}$, and $60{ }^{\circ} \mathrm{C}$. Kamlet-Taft parameters in a LSER regression can quantitatively correlate the kinetics of reaction with the parameters of the solvent. For imidazolium based ILs, reaction rates increase with solvents containing high dipolarity/polarizability and basicity with low acidity. Estimation of the diffusion-limited rate constant confirms that the measured reactions rates represent the intrinsic kinetics. Using the kinetic data, the toxicological and environmental data, and the volatility of the solvents, a method has been proposed to determine the optimal solvents for the synthesis of ILs. Acetone has been shown to possess a number of optimal attributes for the production of ionic liquids.

\section{Acknowledgements}

This material is based upon work supported by the US National Science Foundation under Grant No. CBET-0626313. The author (AMS) appreciates the support of the DuPont Young 
Professor Award. Ms Silvia Nwosu is kindly thanked for some experimental assistance.

\section{References}

1 A. Ahosseini, W. Ren and A. M. Scurto, Chim. Oggi, 2007, 25, $40-42$.

2 M. Haumann and A. Riisager, Chem. Rev., 2008.

3 R. A. Sheldon, R. M. Lu, M. J. Sorgedrager, F. v. Rantwijk and K. R. Seddon, Green Chem., 2002, 4, 147-151.

4 C. Jork, M. Seiler, Y.-A. Beste and W. Arlt, J. Chem. Eng. Data, 2004, 49, 852-857.

5 J. L. Anderson, J. K. Dixon and J. F. Brennecke, Acc. Chem. Res., 2007, 40, 1208-1216.

6 M. B. Shiflett and A. Yokozeki, Chim. Oggi, 2006, 24, 28-30.

7 A. Bösmann, L. Datsevich, A. Jess, A. Lauter, C. Schmitz and P. Wasserscheid, Chem. Commun., 2001, 2494-2495.

8 S. Murugesan and R. J. Linhardt, Curr. Org. Synth., 2005, 2, 437451.

9 R. D. Rogers, and K. R. Seddon, Ionic Liquids IIIB: Fundamentals, Progress, Challenges, and Opportunities: Transformations and Processes, 2005.

10 M. Koel, Crit. Rev. Anal. Chem., 2005, 35, 177-192.

11 R. J. Gale and R. A. Osteryoung, J. Electrochem. Soc., 1980, 127, 2167-2172.

12 J. N. Barisci, G. G. Wallace, D. R. MacFarlane and R. H. Baughman, Electrochem. Commun., 2004, 6, 22-27.

13 W. L. Hough, M. Smiglak, H. Rodriguez, R. P. Swatloski, S. K. Spear, D. T. Daly, J. Pernak, J. E. Grisel, R. D. Carliss, M. D. Soutullo, J. H. Davis and R. D. Rogers, New J. Chem., 2007, 31, 14291436.

14 P. Bonhôte, A. P. Dias, N. Papageorgiou, K. Kalyanasundaram and M. Gratzel, Inorg. Chem., 1996, 35, 1168-1178.

15 S. V. Dzyuba and R. A. Bartsch, PhysChemPhys, 2002, 3, 161-167.

16 J. D. Holbrey, W. M. Reichert, R. P. Swatloski, G. A. Broker, W. R. Pitner, K. R. Seddon and R. D. Rogers, Green Chem., 2002, 5, 407413.

17 D. R. MacFarlane, J. Golding, S. Forsyth, M. Forsyth and G. B. Deacon, Chem. Commun., 2001, 1430-1431.

18 J. S. Wilkes, J. A. Levisky, R. A. Wilson and C. L. Hussey, Inorg. Chem., 1982, 21, 1263-1264.

19 J. F. Brennecke and E. J. Maginn, AICHE J., 2001, 47, 2384-2389.

20 D. A. Waterkamp, M. Heiland, M. Schluter, J. C. Sauvageau, T. Beyersdorff and J. Thoming, Green Chem., 2007, 9, 1084 1090.

21 A. K. Burrell, R. E. Del Sesto, S. N. Baker, T. M. McClesky and G. A. Baker, Green Chem., 2007, 9, 809-809.

22 K. R. Harris, M. Kanakubo and L. A. Woolf, J. Chem. Eng. Data, 2006, 51, 1161-1167.

23 J. M. Crosthwaite, M. J. Muldoon, J. K. Dixon, J. L. Anderson and J. F. Brennecke, J. Chem. Thermodyn., 2005, 37, 559-568.

24 K. Kunkel and G. Maas, Eur. J. Org. Chem., 2007, 3746-3757.

25 E. J. Gonzalez, B. Gonzalez, N. Calvar and A. Dominguez, J. Chem. Eng. Data, 2007, 52, 1641-1648.

26 E. A. Turner, C. C. Pye and R. D. Singer, J. Phys. Chem. A, 2003, 107, 2277-2288.

27 C. Reichardt, Solvent and Solvent Effects in Organic Chemistry 3edn., Wiley-VCH, Weinheim, Germany, 2003.

28 L. W. Deady and D. C. Stillman, Aust. J. Chem., 1976, 29, 1745-1748.

29 Y. Gao and J. M. Shreeve, Synthesis, 2004, 1072-1082.

30 M. M. Kabachnik, Y. A. Khomutova and I. P. Beletskaya, Russ. J. Org. Chem., 1999, 35, 26-27.

31 J. Ropponen, M. Lahtinen, S. Busi, M. Nissinen, E. Kolehmainen and K. Rissanen, New J. Chem., 2004, 28, 1426-1430.

32 J. Sun, D. R. MacFarlane and M. Forsyth, Sol. State Ionics, 1997, 3, $356-362$.

33 T. Nevecna and V. Bekarek, Acta Univ. Palack. Olomuc. Fac. Rerum Natur. Chemica XXXI, 1992, 108, 33-37.

34 A. Skrzypczak and P. Neta, Int. J. Chem. Kinet., 2004, 36, 253-258.

35 N. Menshutkin, Z. Phys. Chem, 1890, 5, 589.

36 C. B. Minnich, L. Küpper, M. A. Liauw and L. Greiner, Catal. Today, 2007, 126, 191-195.

37 R. S. Varma and V. V. Namboodiri, Chem. Commun., 2001, 7, 643644.
38 M. Deetlefs and K. R. Seddon, Green Chem., 2003, 5, 181-186.

39 J.-M. Leveque, G. Cravotto, L. Boffa, W. Bonrath and M. Draye, Synlett, 2007, 2065-2068.

40 A. Grosse-Böwing and A. Jess, Green Chem., 2005, 7, 230-235.

41 A. Grosse-Böwing and A. Jess, Chem. Eng. Sci., 2007, 62, 1760-1769. 42 P. T. Anastas, Clean Solvents, 2002, 819, 1-9.

43 P. Anastas, and J. C. Warner, Green Chemistry: Theory and Practice, Oxford University Press, New York, USA, 1998.

44 P. T. Anastas, Environ. Sci. Technol., 2003, 37, 423a.

45 G. Koller, U. Fischer and K. Hungerbühler, Ind. Eng. Chem. Res., 2000, 39, 960-972.

46 R. L. Lankey and P. T. Anastas, Ind. Eng. Chem. Res., 2002, 41, $4498-4502$.

47 W. McDonough, M. Braungart, P. T. Anastas and J. B. Zimmerman, Environ. Sci. Technol., 2003, 37, 434a-441a.

48 D. Kralisch, D. Reinhardt and G. Kreisel, Green Chem., 2007, 9, $1308-1318$.

49 D. Kralisch, A. Stark, S. Korsten, G. Kreisel and B. Ondruschka, Green Chem., 2005, 7, 301-309.

50 P. G. Jessop, R. Stanley, R. A. Brown, C. A. Eckert, C. L. Liotta, T. T. Ngo and P. Pollet, Green Chem., 2003, 5, 123128.

51 U.S. FDA, 2007, http://vm.cfsan.fda.gov/ dms/eafus.html.

52 U.S. FDA, CFSAN/Office of Food Additive Safety, 2006, http://www.cfsan.fda.gov/ dms/opa-appa.html\#ftnE.

53 Rowan University, http://www.rowan.edu/greenengineering, accessed: January 20, 2008.

54 C. S. Slater and M. J. Savelski, J. Environ. Sci. Health Part A, 2007, 42, 1595-1605.

55 Corporate Environment and Safety Product Stewardship Guide: Solvent Selection Guidelines, GlaxoSmithKline(GSK) pharmaceuticals, 2003.

56 M. J. Muldoon, C. M. Gordon and I. R. Dunkin, J. Chem. Soc. Perkin Trans. 2, 2001, 433-435.

57 C. Reichardt, Green Chem., 2005, 7, 339-351.

58 M. J. Kamlet and R. W. Taft, J. Am. Chem. Soc., 1976, 2886-2894.

59 M. J. Kamlet and R. W. Taft, J. Am. Chem. Soc., 1976, 377-383.

60 M. J. Kamlet, J. L. Abboud and R. W. Taft, J. Am. Chem. Soc., 1977, 99, 6027-6037.

61 C. Laurence, P. Nicolet and M. T. Dalati, J. Phys. Chem., 1994, 58075816.

62 M. J. Kamlet, J. M. Abboud, M. H. Abraham and R. W. Taft, J. Org. Chem., 1983, 2877-2887.

63 J. McLaren, J. Chem. Technol. Biotechnol., 2000, 927-932.

64 D. Wilke, Appl. Microbiol. Biotechnol., 1999, 135-145.

65 M. H. Abraham, Prog. Phys. Org. Chem., 1974, 11, 1-87.

66 E. D. Hughes, Trans. Faraday Soc., 1941, 37, 603-637.

67 E. D. Hughes, M. L. Dhar, C. K. Ingold, A. M. M. Mandour, G. A. Maw and L. I. Woolf, J. Chem. Soc., 1948, 2093-2119.

68 E. D. Hughes and C. K. Ingold, J. Chem. Soc., 1935, 244-255.

69 Arrhenius, Z. Physik. Chem., 1889, 4, 226.

70 H. Erying, Chem. Rev., 1935, 17, 65-77.

71 H. Eyring, J. Chem. Phys., 1935, 3, 107-115.

72 U. A. Chaudry and P. L. A. Popelier, J. Phys. Chem. A, 2003, 107, $4578-4582$

73 J. F. Mata-Segreda, Int. J. Chem. Kinet., 2000, 32, 67-71.

74 D. Stefanidis and W. P. Jencks, J. Am. Chem. Soc., 1993, 115, 60456050.

75 L. Singh, R. T. Singh and R. C. Jha, J. Indian Chem. Soc., 1981, 58, 966-969.

76 A. B. Manning, J. Chem. Soc., 1921, 119, 2079-2087.

77 P. Haberfield, A. Nudelman, A. Bloom, R. Bloom and H. Ginsberg, J. Org. Chem., 1971, 36, 1792-1795.

78 P. Atkins, Physical Chemistry 6th Edition, W.H. Freeman and Company, New York, 1998.

79 P. Bonhote, A.-P. Dias, N. Papageirgiou, K. Kalyanasundaram and M. Gratzel, Inorg. Chem., 1996, 35, 1168-1178.

80 M. Ue, M. Takeda, T. Takahashi and M. Takehara, Electrochem. Solid-State Lett., 2002, 5, A119-A121.

81 L. Leclercq, I. Suisse, G. Nowogrocki and F. Agbossou-Niedercorn, Green Chem., 2007, 9, 1097-1103.

82 M. Yoshizawa, M. Hirao, K. Ito-Akita and H. Ohno, J. Mater. Chem., 2001, 11, 1057-1062.

83 J. Schleicher, A. Ahosseini and A. M. Scurto, manuscript in preparation, 2008. 
84 V. V. Zverlov, O. Berezina, G. A. Velikodvotskaya and W. H. Schwarz, Appl. Microbiol. Biotechnol, 2006, 71, 587597.

85 S. N. V. K. Aki, A. M. Scurto and J. F. Brennecke, Ind. Eng. Chem. Res., 2006, 45, 5574-5585.

86 A. M. Scurto, S. N. V. K. Aki and J. F. Brennecke, J. Am. Chem. Soc., 2002, 124, 10276-10277.

87 A. M. Scurto, S. N. V. K. Aki and J. F. Brennecke, Chem. Commun., 2003, 572-573.
88 A. M. Scurto, Ph.D. Dissertation, University of Notre Dame, 2002.

89 J. Schleicher, MS Thesis, University of Kansas, 2007.

90 O. Levenspiel, Chemical Reaction Engineering, Wiley, New York, USA, 1998

91 M. J. Kamlet, T. N. Hall, J. Boykin and R. W. Taft, J. Org. Chem., $1979,44,2599-2604$.

92 D. Lide, CRC Handbook of Chemistry and Physics 88th edn., CRC Press, Boca Raton, 2007.

93 M. Temprado and J. S. Chickos, Thermochim. Acta, 2005, 435, 49-56. 